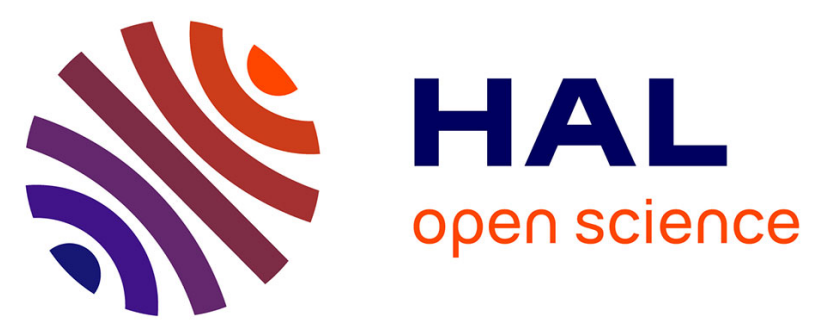

\title{
High temperature mechanical behavior of tube stackings \\ - Part I: Microstructural and mechanical characterization of Inconel 600 constitutive material
}

V. Marcadon, C. Davoine, D. Lévêque, A. Rafray, F. Popoff, N. Horezan, D. Boivin

\section{To cite this version:}

V. Marcadon, C. Davoine, D. Lévêque, A. Rafray, F. Popoff, et al.. High temperature mechanical behavior of tube stackings - Part I: Microstructural and mechanical characterization of Inconel 600 constitutive material. Materials Science and Engineering: A, 2016, 677, p. 540-548. 10.1016/j.msea.2016.07.088 . hal-01393509

\section{HAL Id: hal-01393509 \\ https://hal.science/hal-01393509}

Submitted on 7 Nov 2016

HAL is a multi-disciplinary open access archive for the deposit and dissemination of scientific research documents, whether they are published or not. The documents may come from teaching and research institutions in France or abroad, or from public or private research centers.
L'archive ouverte pluridisciplinaire HAL, est destinée au dépôt et à la diffusion de documents scientifiques de niveau recherche, publiés ou non, émanant des établissements d'enseignement et de recherche français ou étrangers, des laboratoires publics ou privés. 


\title{
High temperature mechanical behavior of tube stackings - Part I: Microstructural and mechanical characterization of Inconel $囚 600$ constitutive material
}

\author{
V. Marcadon, C. Davoine, D. Lévêque, A. Rafray, \\ F. Popoff, N. Horezan and D. Boivin \\ Onera - The French Aerospace Lab, \\ F-92322 Châtillon, France.
}

September 16, 2016

\begin{abstract}
This paper is the first part of a set of two papers dedicated to the mechanical behavior of cellular materials at high temperatures. For that purpose, cellular materials made of brazed tube stacking cores have been considered here. This paper addresses the characterization of the elasto-viscoplastic properties of the constitutive material of the

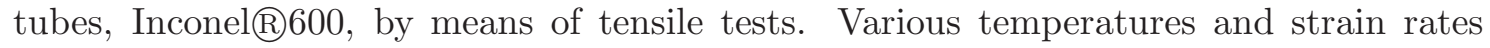
were investigated, from room temperature to $800^{\circ} \mathrm{C}$, in order to study the influence of both the brazing heat treatment and the test temperature on the mechanical properties of Inconel $囚 600$. Whereas the heat treatment drastically decreases the strength of the tubes, a significant viscous effect is revealed at $800^{\circ} \mathrm{C}$. Electron backscattered diffraction
\end{abstract}

*Metallic Materials and Structures Department, Tel: +33 146734524; Fax: +33 146734891; E-mail: Vincent.Marcadon@onera.fr 
analyses carried out post-mortem on samples showed that both dynamic recrystallization and recovery occurred during tensile tests performed at $800^{\circ} \mathrm{C}$, especially at lower strain rates. In contrast, a highly deformed and textured microstructure was observed for the tubes loaded at lower temperatures.

keywords: Metallic tube stackings, Cellular materials, High temperature behavior, Mechanical characterization, Microstructural characterization.

\section{Introduction}

Metallic cellular structures, such as metal foams, honeycombs, truss lattices, and hollow-sphere or tube stackings, for instance, have been abundantly studied for several years because of their potential for the development of new multi-functional and lightweight structures $[1,2]$. In order to address this issue, tube stackings have been considered here as a 'model' cellular structure. Indeed, the case of tube stackings is particular, since it is a quite new cellular architecture that has been barely studied, despite presenting an extruded character that is very convenient to develop 2D modeling. Moreover, the elementary tubes can be bought easily and both their geometrical and mechanical properties are very reproducible. Thus, regular stackings can be manufactured with only few defects, which enables a very rich dialogue between experiment and modeling involving large deformations and contact issues. The main mechanism that governs the mechanical behavior of tube stackings is the localized plasticity in the walls of the constitutive cells $[3,4]$. Therefore, this is significantly different from the case of honeycombs loaded transversally, for which buckling and cell wall instabilities are observed [5, 6]. It is mainly a question of ratio between the cell wall thickness and the cell diameter. The reader can refer to the companion paper of this one (see Part II [7]) for a more complete review on the mechanical behavior of cellular structures. Here, focus is on both the mechanical and microstructural properties of Inconel@600 as constitutive material of the tube stacking structure studied.

Inconel@600 is a commercially available Ni-Cr-Fe alloy that exhibits a good combination of strength, formability and environmental resistance at high temperatures. This combination of 
properties makes this material ideally suited for structural components in chemical processing equipment, nuclear reactors or aerospace applications, for instance. In order to provide a good understanding of the stress corrosion cracking resistance of Inconel@600, microstructural changes that occur when this alloy is heat-treated in the temperature range of $600^{\circ} \mathrm{C}$ to $900^{\circ} \mathrm{C}$ have been widely studied [8,9]. Bruemmer et al [10] suggested that the distribution of the grain boundary carbides may induce a mechanical effect, since carbides reduce the crack tip stress state by crack tip blunting. The effect of heat treatments on the mechanical properties of Inconel@600 has been studied also, in particular the role of the carbides located at grain boundaries [11]. Extensive grain boundary cracks are observed on the fracture surfaces of tensile and impact specimens with continuous grain boundary carbides, decreasing the area reduction observed at the rupture. The shortest delay time for precipitation is observed between $800^{\circ} \mathrm{C}$ and $900^{\circ} \mathrm{C}$. At higher temperatures, grain growth occurs when the alloy is heated to about $980^{\circ} \mathrm{C}$. At this temperature, the carbide particles finely dispersed into the microstructure, which inhibit grain growth, begin to coalesce. Carbide solution begins at about $1040^{\circ} \mathrm{C}$, whereas solution annealing, observed above $1190^{\circ} \mathrm{C}$, results in the dissolution of all of the carbides [12], hence an increased grain size. Moreover, it has been shown that the mechanical properties of

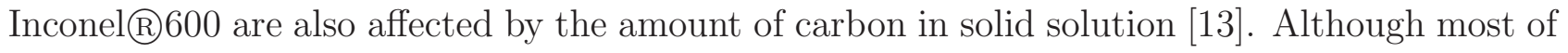
the carbon resides in carbides, and only a small fraction exists as interstitial solution because of the high chromium content (about 16 wt.\%) in Inconel@600, the interaction of carbon with mobile dislocations results in dynamic strain ageing. In order to have a better understanding of the mechanisms involved in ultra-fine grain processing techniques, grain boundary engineering, or welding, the effects of both the deformation level and temperature on the microstructure of Inconel@600 have been investigated recently [14]. Depending on the deformation level and the temperature, various mechanisms, such as static and dynamic recrystallizations or dynamic recovery, may dominate and affect the development of microstructures. In particular, these mechanisms contribute to reducing the strain hardening during the deformation. Dynamic recrystallization was also observed in Inconel@600 friction stir welded samples [15]. Blaizot et al 
[16] recently proposed a model accounting for such complex interactions, but for Inconel@690.

They showed that, for this alloy, the dislocation density is the main microstructural parameter governing the mechanical behavior for the experimental conditions that they considered.

This work is aimed at studying the elasto-viscoplastic properties of Inconel@600, in order to be able to propose a rich dialogue between experiment and modeling when further characterizing the mechanical behavior of tube stacking structures at high temperatures (see Part II [7]). Although this characterization is presented in Part II only, Section 2 describes the tube stacking studied and its process route to precise the brazing heat treatment applied to the constitutive material. Then Section 3 addresses the characterization of the elasto-viscoplastic properties of Inconel@600, as constitutive material of the tubes, by means of tensile tests performed on single tubes at different strain rates. Various temperatures were investigated, from room temperature to $800^{\circ} \mathrm{C}$ in order to study the influence of both the brazing heat treatment and the test temperature. In order to investigate microstructural evolutions induced by both the heat treatment and the test conditions, electron backscattered diffraction (EBSD) analyses were carried out post-mortem on the samples. They are described in Section 4 in terms of deformation mechanisms, twinning and microstructural changes in the grains.

\section{Studied material}

The method for fabricating a 'model' cellular structure consisting of regularly stacked circular tubes is briefly reported here. The small sandwich structure was processed by using a brazing heat treatment. It consisted of two Inconel@ 600 skins with a thickness of $1 \mathrm{~mm}$ and a $5 \times 5$-tube stacking core. The tubes were made of Inconel@600 also, and their outer diameter and thickness were equal to $4 \mathrm{~mm}$ and $250 \mu \mathrm{m}$, respectively. These seamless tubes were manufactured by Alloyshop using extrusion and their chemical composition is given in Table 1. This nickelchromium-iron alloy is a standard engineering material for applications that require resistance to corrosion at high temperatures.

The tubes were bonded to each other and to the skins by using Ni-1.5B-19.0Cr-7.3Si-0.08C 
Table 1: Chemical composition of Inconel@600.

\begin{tabular}{ccccccccc}
\hline Element & $\mathrm{Cr}$ & $\mathrm{Fe}$ & $\mathrm{Si}$ & $\mathrm{Mn}$ & $\mathrm{C}$ & $\mathrm{Cu}$ & $\mathrm{S}$ & $\mathrm{Ni}$ \\
\hline wt.\% (weight content) & 15.5 & 8.0 & 0.5 & 1.0 & 0.15 & 0.5 & 0.01 & bal. \\
\hline
\end{tabular}

(wt.\%) braze foils. They were stacked in a graphite die lined with Inconel@600 skins, positioned at the top and at the bottom of the stacking in order to provide the sandwich structures. The internal faces of the graphite die were coated with a boron nitride layer to avoid the chemical interactions between carbon and the metallic structure. The main advantage of this braze ensues from its good oxidation resistance properties, compared to those of the Ni-11.0P wt.\% braze that we have used previously for room temperature applications, for instance [3, 4]. A stacking following a square pattern in its transversal plane was produced by this technique (Fig. 1(a)), since this particular braze was available under the shape of $50 \mu \mathrm{m}$ thickness foils only. The 'square stacking' was achieved by alternatively stacking a layer of tubes and three braze foils. The bonding was achieved by applying a heat treatment in a vacuum furnace. The Ni-1.5B-19.0Cr-7.3Si-0.08C wt.\% alloy is liquid above $1150^{\circ} \mathrm{C}$. Thus, the heat treatment chosen here consisted in an increase in the temperature at $100^{\circ} \mathrm{Cmin}^{-1}$ up to $1170^{\circ} \mathrm{C}$, then followed by a dwell of $15 \mathrm{~min}$ at $1170^{\circ} \mathrm{C}$ and, finally, followed by the natural cooling of the furnace. At $1170^{\circ} \mathrm{C}$ the liquid concentrated at the contact lines by capillarity, hence metallurgical joints were created between the tubes after cooling.

Energy dispersive spectroscopy (EDS) analyses showed that the braze joint consisted of three distinct phases, brittle intermetallic chromium borides and nickel silicides in a ductile Nirich solid solution. These phases were visible in scanning electron microscopy (SEM) chemical contrast images (Fig. 1(b)). Moreover, the mean grain size in the tube walls was rather large. It varied between 100 and $150 \mu \mathrm{m}$. This could result from the brazing heat treatment, despite its short duration. SEM analyses revealed that the braze joint width was around 1.43 $\mathrm{mm}$, although there was a slight difference between the horizontal joints and the vertical ones resulting from the fact that the braze foils were initially placed horizontally between the tube layers themselves and between the tube layers and the skins; the mean width for the horizontal 


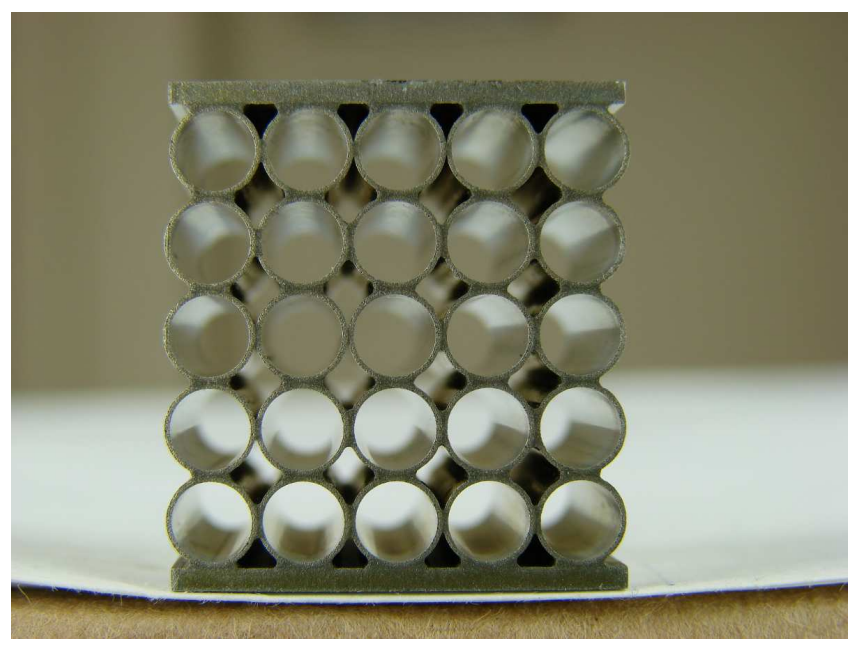

(a)

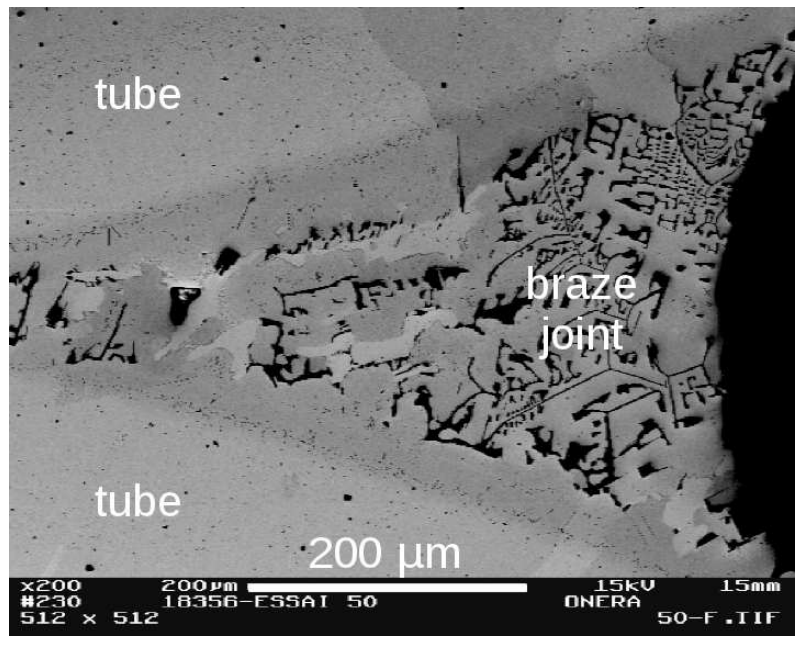

(b)

Figure 1: a) Tube stacking performed b) EDS image of a braze joint between two neighboring tubes (chromium borides are in black, nickel silicides are in light grey and the Ni-rich solid solution is in medium grey) .

braze joints was equal to $1.63 \mathrm{~mm}$, whereas it was equal to $1.23 \mathrm{~mm}$ for the vertical ones. The length of the tubes was equal to $20 \mathrm{~mm}$ after the electro-discharge cutting of the samples. The density of the cellular structure was about $2.29 \mathrm{~g} \mathrm{~cm}^{-3}$ compared to that of the constitutive material, which was equal to $8.25 \mathrm{~g} \mathrm{~cm}^{-3}$.

\section{Mechanical behavior of the constitutive material}

This section is aimed at characterizing the mechanical properties of the tube material Inconel@600 in-situ. Indeed, the effective work-hardening of cellular structures results from both architectural effects (e.g., stress localization) and the constitutive material hardening properties $[3,4,17,18,19]$. This first step is thus necessary to be able to propose a predictive model of the mechanical behavior of the tube stacking structure and to enrich the comparison with the experiment detailed in Part II of this work [7]. In order to address the influence of the test temperature on the elasto-viscoplastic behavior of Inconel@600, uni-axial tensile tests on single tubes have been performed at various temperatures and strain rates. 


\subsection{Tensile tests on single tubes}

The experiments have been performed using an electro-mechanical testing machine (see Fig. 2). The length of the tubes was $170 \mathrm{~mm}$ and their extremities were handled in holding jaws. Small $20 \mathrm{~mm}$ length rods were inserted into the ends of the tubes to allow their holding and to avoid their collapse and their sliding during the tests, which would have altered the measurements. The loading displacement was controlled at various crosshead speeds: $0.4 \mathrm{~mm} \mathrm{~min}^{-1}, 4.5$ $\mathrm{mm} \mathrm{min}^{-1}$ and $47.0 \mathrm{~mm} \mathrm{~min}^{-1}$. Three test temperatures were considered: room temperature (labelled RT in the captions in the following), $600^{\circ} \mathrm{C}$ and $800^{\circ} \mathrm{C}$. The longitudinal elongation of the tubes was measured using an extensometer placed in the furnace, whereas the holding jaws were outside the furnace. Such an experimental device was aimed at preventing some error in the measurement of the strain resulting from the heat gradient that existed in the portion of the samples outside of the furnace, hence an improved identification of the plastic properties and Young modulus especially. The real strain rates applied on the portion of the samples inside the furnace, in which the strain was homogeneous, have been computed from the strain measurements provided by the extensometer. Several samples were tested for each test temperature and strain rate, not only after the brazing heat treatment but also before.

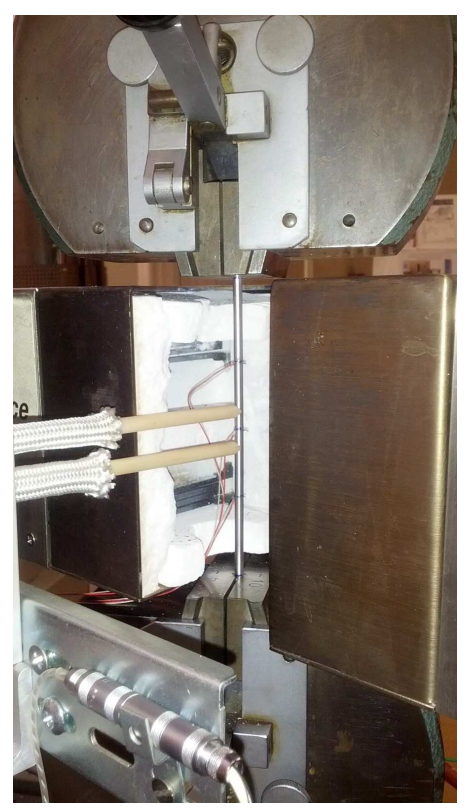

Figure 2: Experimental setup for the tensile tests on single tubes. 
In the following, the as-received tubes are labelled NHT, for no heat treatment, and the treated ones are labelled BHT, for brazing heat treatment. The stress-strain curves are plotted in Figs. 3(a) and 3(b) and the results are detailed in the next section. They show a quite good test reproducibility. However, the main conclusion from these tests is the fact that the heat treatment drastically decreases the strength of the tubes, so the mechanical behavior of the tube constitutive material is strongly altered. Such a decrease can be explained by the fact that, before the brazing heat treatment, the tubes were greatly hardened because of their cold drawing process. The heat treatment acts as a recovery treatment, hence the drop in the yield stress, but the recovery of higher hardening capabilities. A decrease in the mechanical behavior of Inconel@600 is also observed when the test temperature is increased. Furthermore, although no viscosity effect is observed at room temperature and $600^{\circ} \mathrm{C}$, a significant one appears at $800^{\circ} \mathrm{C}$. It is also worth noting that, for the tests at $800^{\circ} \mathrm{C}$, the mechanical responses before and after the heat treatment are considerably closer than for those at room temperature and $600^{\circ} \mathrm{C}$. Therefore, the test temperature acts as a recovery treatment also, if it is high enough.

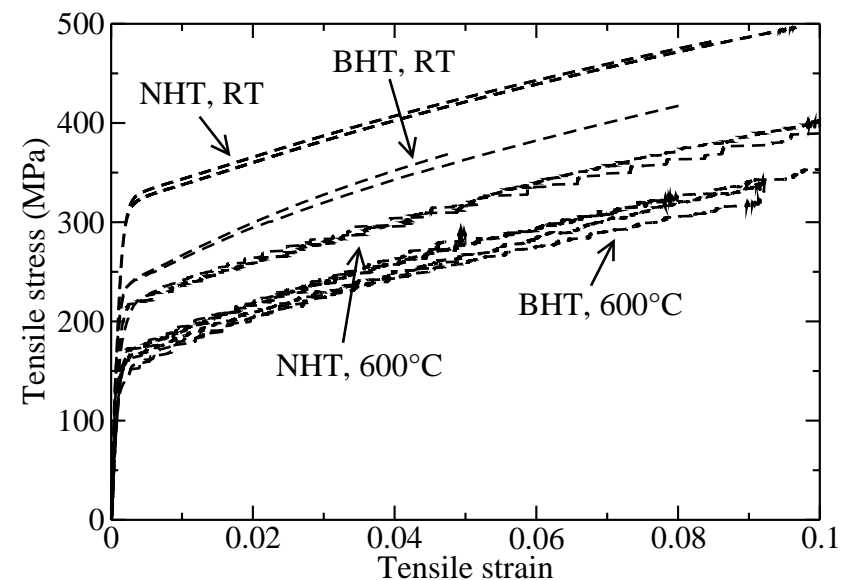

(a)

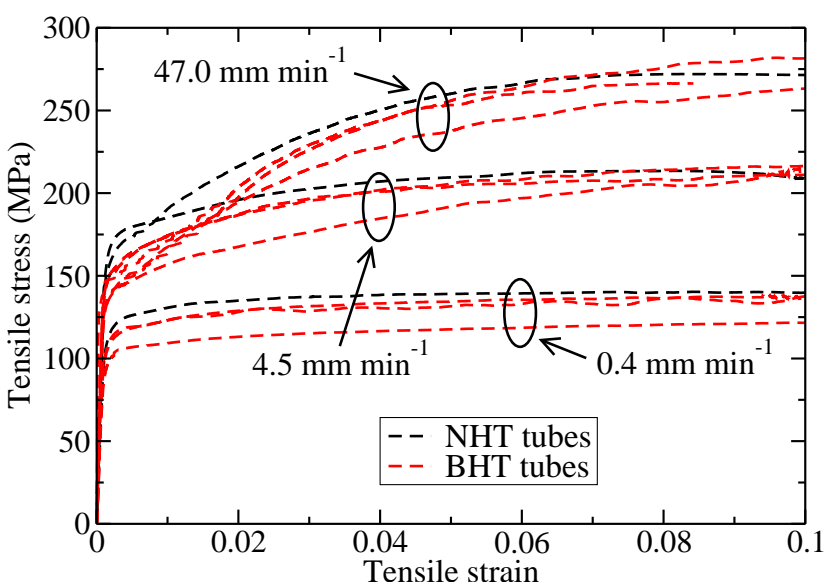

(b)

Figure 3: Stress-strain curves resulting from the tensile tests on both NHT and BHT single tubes a) at room temperature and $600^{\circ} \mathrm{C}$ b) at $800^{\circ} \mathrm{C}$.

Some mechanical properties, such as the Young modulus $E_{m}$ and the stress value for $0.2 \%$ plastic strain $\sigma_{0.2 m}$ have been identified from the experimental stress-strain curves. They are 
given in Table 2 with the test conditions for each sample. For the NHT tubes, the mean values for the Young modulus are equal to $215.0 \pm 14.0 \mathrm{GPa}, 182.0 \pm 28.0 \mathrm{GPa}$ and $136.0 \pm 22.0$ $\mathrm{GPa}$ at room temperature, $600^{\circ} \mathrm{C}$ and $800^{\circ} \mathrm{C}$, respectively. The corresponding mean values for the BHT tubes are equal to 265.0 \pm 8.0 GPa, 175.0 \pm 21.0 GPa and 136.0 \pm 25.0 GPa. With regard to the mean values for $\sigma_{0.2 m}$, these are equal to $323.0 \pm 3.0 \mathrm{MPa}, 218.0 \pm 1.0 \mathrm{MPa}$ and $155.0 \pm 28.0 \mathrm{MP}$ for the NHT tubes,and 240.0 $\pm 1.0 \mathrm{MPa}, 165.0 \pm 8.0 \mathrm{MPa}$ and $131.0 \pm 19.0$ MPa for the BHT tubes. Unlike the Young modulus, the mean values for $\sigma_{0.2 m}$ show a larger scattering at $800^{\circ} \mathrm{C}$ compared to those at room temperature or at $600^{\circ} \mathrm{C}$. This ensues from the fact that this quantity is measured after the beginning of plasticity, hence it depends strongly on the strain rate in case of viscosity $\left(\right.$ at $\left.800^{\circ} \mathrm{C}\right)$.

In the literature, the Young modulus of Inconel@6 600 is equal to $214 \mathrm{GPa}$ at $22^{\circ} \mathrm{C}, 180 \mathrm{GPa}$ at $600^{\circ} \mathrm{C}$ and $164 \mathrm{GPa}$ at $800^{\circ} \mathrm{C}$ (http://www.specialmetals.com/products/inconelalloy600.php), respectively. Thus, the mean values identified experimentally for this quantity are very close to those of the literature despite some experimental scattering. As concerns $\sigma_{0.2 m}$, it varies between $170 \mathrm{MPa}$ and $345 \mathrm{MPa}$ at room temperature in the literature, but this quantity depends strongly on the process route and the history of the plastic loading explaining why there is no precise value. We can only conclude that the experimental values measured are consistent with those of the literature.

\subsection{Identification of an elasto-viscoplastic model from room tem- perature to $800^{\circ} \mathrm{C}$}

The mechanical properties of Inconel@ 600 have been identified for the BHT material by fitting the mechanical responses of a homogeneous equivalent medium (HEM) to the experimental stress-strain curves between 0 and $8 \%$ of tensile strain, and by using the Levenberg-Marquardt optimization method. A first identification has been attempted, using a classical mono-potential elasto-viscoplastic model, but it failed to capture the saturation of the viscous effect observed at

$800^{\circ} \mathrm{C}$ when the strain rate was increased (see Fig. 3(b)). Consequently, we have proposed a new 
Table 2: Mechanical properties of Inconel@600 identified experimentally from the tensile tests on single tubes. Samples 23 and 24 are mentioned in the table since their stress-strain curves are plotted in Figs. 3(b) and $4(\mathrm{~b})$, but $E_{m}$ and $\sigma_{0.2 m}$ could not be measured in those cases because of too noisy curves.

\begin{tabular}{|c|c|c|c|c|c|c|}
\hline & & Temperature & Loading rate & Strain rate & $E_{m}(\mathrm{GPa})$ & $\sigma_{0.2 m}(\mathrm{MPa})$ \\
\hline \multirow[t]{7}{*}{ NHT } & Sample 1 & RT & $0.4 \mathrm{~mm} \mathrm{~min}^{-1}$ & $5.0 \times 10^{-5} \mathrm{~s}^{-1}$ & 205.0 & 321.0 \\
\hline & Sample 2 & $\mathrm{RT}$ & $47.0 \mathrm{~mm} \mathrm{~min}^{-1}$ & $5.7 \times 10^{-3} \mathrm{~s}^{-1}$ & 225.0 & 325.0 \\
\hline & Sample 3 & $600^{\circ} \mathrm{C}$ & $0.4 \mathrm{~mm} \mathrm{~min}^{-1}$ & $5.0 \times 10^{-5} \mathrm{~s}^{-1}$ & 202.0 & 218.0 \\
\hline & Sample 4 & $600^{\circ} \mathrm{C}$ & $47.0 \mathrm{~mm} \mathrm{~min}^{-1}$ & $5.9 \times 10^{-3} \mathrm{~s}^{-1}$ & 162.0 & 217.0 \\
\hline & Sample 5 & $800^{\circ} \mathrm{C}$ & $0.4 \mathrm{~mm} \mathrm{~min}^{-1}$ & $1.2 \times 10^{-4} \mathrm{~s}^{-1}$ & 112.0 & 123.0 \\
\hline & Sample 6 & $800^{\circ} \mathrm{C}$ & $4.5 \mathrm{~mm} \mathrm{~min}^{-1}$ & $1.1 \times 10^{-3} \mathrm{~s}^{-1}$ & 141.0 & 176.0 \\
\hline & Sample 7 & $800^{\circ} \mathrm{C}$ & $47.0 \mathrm{~mm} \mathrm{~min}^{-1}$ & $8.5 \times 10^{-3} \mathrm{~s}^{-1}$ & 155.0 & 167.0 \\
\hline \multirow[t]{17}{*}{$\mathrm{BHT}$} & Sample 8 & RT & $4.5 \mathrm{~mm} \mathrm{~min}^{-1}$ & $5.1 \times 10^{-4} \mathrm{~s}^{-1}$ & 270.0 & 239.3 \\
\hline & Sample 9 & $\mathrm{RT}$ & $4.5 \mathrm{~mm} \mathrm{~min}^{-1}$ & $5.0 \times 10^{-4} \mathrm{~s}^{-1}$ & 259.0 & 240.7 \\
\hline & Sample 10 & $600^{\circ} \mathrm{C}$ & $0.4 \mathrm{~mm} \mathrm{~min}^{-1}$ & $6.7 \times 10^{-5} \mathrm{~s}^{-1}$ & 180.0 & 172.4 \\
\hline & Sample 11 & $600^{\circ} \mathrm{C}$ & $0.4 \mathrm{~mm} \mathrm{~min}^{-1}$ & $6.7 \times 10^{-5} \mathrm{~s}^{-1}$ & 145.0 & 166.7 \\
\hline & Sample 12 & $600^{\circ} \mathrm{C}$ & $4.5 \mathrm{~mm} \mathrm{~min}^{-1}$ & $6.0 \times 10^{-4} \mathrm{~s}^{-1}$ & 186.0 & 157.1 \\
\hline & Sample 13 & $600^{\circ} \mathrm{C}$ & $4.5 \mathrm{~mm} \mathrm{~min}^{-1}$ & $6.0 \times 10^{-4} \mathrm{~s}^{-1}$ & 160.0 & 171.0 \\
\hline & Sample 14 & $600^{\circ} \mathrm{C}$ & $4.5 \mathrm{~mm} \mathrm{~min}^{-1}$ & $6.0 \times 10^{-4} \mathrm{~s}^{-1}$ & 204.0 & 167.1 \\
\hline & Sample 15 & $600^{\circ} \mathrm{C}$ & $47.0 \mathrm{~mm} \mathrm{~min}^{-1}$ & $6.2 \times 10^{-3} \mathrm{~s}^{-1}$ & 175.0 & 153.3 \\
\hline & Sample 16 & $800^{\circ} \mathrm{C}$ & $0.4 \mathrm{~mm} \mathrm{~min}^{-1}$ & $1.3 \times 10^{-4} \mathrm{~s}^{-1}$ & 119.0 & 116.1 \\
\hline & Sample 17 & $800^{\circ} \mathrm{C}$ & $0.4 \mathrm{~mm} \mathrm{~min}^{-1}$ & $1.3 \times 10^{-4} \mathrm{~s}^{-1}$ & 114.0 & 115.2 \\
\hline & Sample 18 & $800^{\circ} \mathrm{C}$ & $0.4 \mathrm{~mm} \mathrm{~min}^{-1}$ & $1.3 \times 10^{-4} \mathrm{~s}^{-1}$ & 115.0 & 103.9 \\
\hline & Sample 19 & $800^{\circ} \mathrm{C}$ & $4.5 \mathrm{~mm} \mathrm{~min}^{-1}$ & $8.8 \times 10^{-4} \mathrm{~s}^{-1}$ & 160.0 & 153.5 \\
\hline & Sample 20 & $800^{\circ} \mathrm{C}$ & $4.5 \mathrm{~mm} \mathrm{~min}^{-1}$ & $8.8 \times 10^{-4} \mathrm{~s}^{-1}$ & 180.0 & 141.2 \\
\hline & Sample 21 & $800^{\circ} \mathrm{C}$ & $47.0 \mathrm{~mm} \mathrm{~min}^{-1}$ & $7.5 \times 10^{-3} \mathrm{~s}^{-1}$ & 142.0 & 143.2 \\
\hline & Sample 22 & $800^{\circ} \mathrm{C}$ & $47.0 \mathrm{~mm} \mathrm{~min}^{-1}$ & $7.5 \times 10^{-3} \mathrm{~s}^{-1}$ & 125.0 & 145.6 \\
\hline & Sample 23 & $800^{\circ} \mathrm{C}$ & $4.5 \mathrm{~mm} \mathrm{~min}^{-1}$ & $8.8 \times 10^{-4} s^{-1}$ & - & - \\
\hline & Sample 24 & $800^{\circ} \mathrm{C}$ & $47.0 \mathrm{~mm} \mathrm{~min}^{-1}$ & $7.5 \times 10^{-3} \mathrm{~s}^{-1}$ & - & - \\
\hline
\end{tabular}

identification of the behavior of Inconel@600 by considering a bi-potential elasto-viscoplastic model. Such a more complex model enables the respective contributions of viscosity and plasticity to be dissociated [20]. It allows all of the features of the behavior of Inconel@600 observed from room temperature to $800^{\circ} \mathrm{C}$ to be obtained.

The model equations are the following. The constitutive material was assumed to be elastoviscoplastic isotropic. The elasticity was supposed to be governed by Hooke law:

$$
\underline{\underline{\sigma}}=\frac{E_{m}}{1+\nu_{m}}\left(\underline{\underline{\underline{\varepsilon_{e}}}}+\frac{\nu_{m}}{1-2 \nu_{m}} \operatorname{tr}\left(\underline{\underline{\varepsilon_{e}}}\right) \underline{\underline{i}}\right)
$$


where $\underline{\underline{\sigma}}, \underline{\underline{\varepsilon_{e}}}$ and $\underline{\underline{i}}$ denote the stress tensor, the elastic part of the strain tensor $\underline{\underline{\varepsilon}}$ and the secondorder identity tensor, respectively. $E_{m}$ and $\nu_{m}$ are the Young modulus and the Poisson ratio for the constitutive material. The plastic and viscous parts of the strain tensor are noted $\underline{\underline{\varepsilon_{p}}}$ and $\underline{\underline{\varepsilon_{v}}}$, respectively, with the classical decomposition of the total strain $\underline{\underline{\varepsilon}}=\underline{\underline{\varepsilon_{e}}}+\underline{\underline{\varepsilon_{p}}}+\underline{\underline{\varepsilon_{v}}}$.

A Von Mises criterion was chosen for the yield surface:

$$
\mathcal{F}(\underline{\underline{\sigma}})=J(\underline{\underline{\sigma}})-R(p)
$$

where $J(\underline{\underline{\sigma}})=\sqrt{(3 / 2) \underline{\underline{s}}: \underline{\underline{s}}}$ and $\underline{\underline{s}}$ denotes the deviatoric stress tensor: $\underline{\underline{s}}=\underline{\underline{\sigma}}-(1 / 3) \operatorname{tr}(\underline{\underline{\sigma}}) \underline{\underline{i}} . R(p)$ is the instantaneous yield stress, which results from the constitutive material hardening, with $p=\int_{0}^{t} \sqrt{(2 / 3) \underline{\underline{\varepsilon_{p}}}: \underline{\underline{\dot{\varepsilon}_{p}}}} d t$ denoting the cumulative plastic strain. Note that this is a purely plastic potential.

Since the stress-strain curves showed an inflection of the hardening when increasing the strain level, on the basis of our previous works [4] a sum of non-linear exponential hardening terms has been used to account for such a plasticity saturation phenomenon:

$$
R(p)=\sigma_{y m}+\sum_{i=1}^{3} Q_{i m}\left(1-\exp \left(-b_{i m} p\right)\right)
$$

where $\sigma_{y m}$ denotes the yield stress and the $Q_{i m}$ and the $b_{i m}$ are the coefficients of the non-linear hardening terms. Accounting for such a saturating hardening was critical in view of modeling aspects, because the stress concentration around the braze joints can result in considerably high localized cumulative plastic strain values, inducing significant overestimation of the plastic contribution.

The viscous contribution was governed by Norton law:

$$
\underline{\underline{\underline{\varepsilon_{v}}}}=\left(\frac{J(\underline{\underline{\sigma}})}{D_{m}}\right)^{n_{m}-1} \frac{\underline{\underline{s}}}{D_{m}}
$$

where $n_{m}$ and $D_{m}$ denote the Norton exponent and the drag stress of the constitutive material, 
respectively. ${\dot{\varepsilon_{v}}}_{=}$is the time derivative of the cumulative viscous strain. Note that this power law contains no plastic contribution and has no activation threshold. Other models exist in the literature to account for behaviors exhibiting different viscosity regimes, by using hyperbolic sine based equations $[21,22]$. These models are commonly used in creep-fatigue applications and they provide very good results [23, 24, 25]. However, they assume coupled plastic and viscous contributions because they are only mono-potential models. Although the particular case of hyperbolic sine models has not been evaluated here, when trying to use a mono-potential model with two Norton terms to account for two distinct viscous regimes, before opting for a bi-potential formulation, this was not efficient enough to capture the behavior features observed.

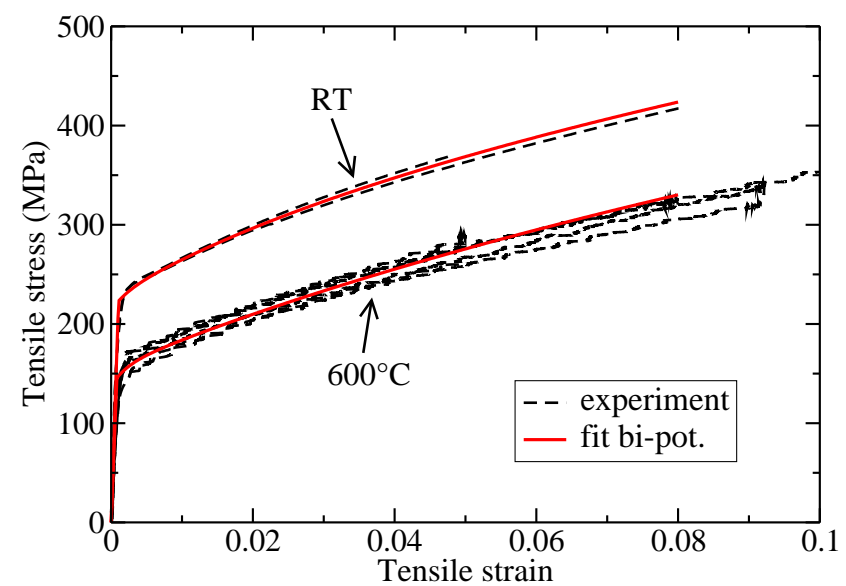

(a)

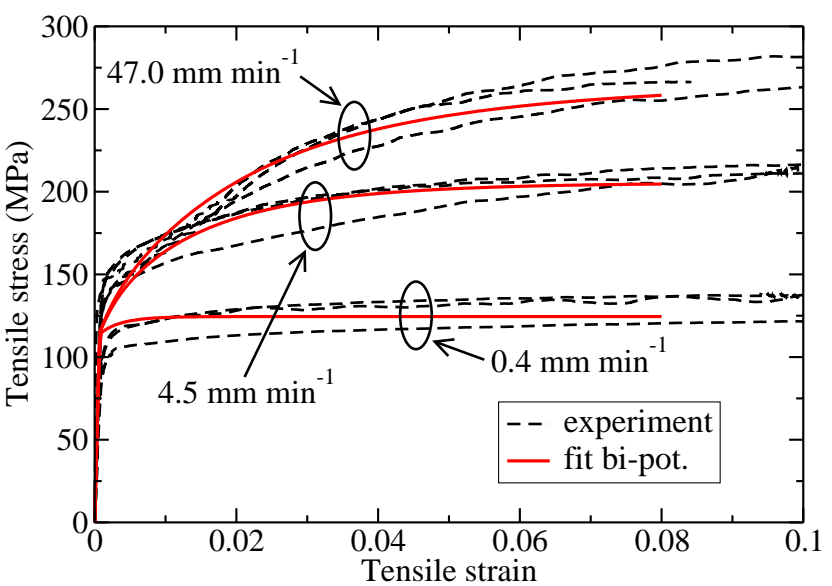

(b)

Figure 4: Stress-strain curves resulting from the tensile tests on the BHT single tubes and their fitted mechanical responses a) at room temperature and $600^{\circ} \mathrm{C}$ b) at $800^{\circ} \mathrm{C}$.

First, we have only considered the tensile tests at room temperature and $600^{\circ} \mathrm{C}$, which have not shown any viscosity effect and which have been analyzed by the following fitting procedure. For these two temperatures, all of the stress-strain curves were almost superimposed, whatever the strain rate. For each test temperature, the fitted curves have been optimized simultaneously taking into account all of the samples tested at this given temperature. Due to the lack of experimental data on the tangential strain, only the longitudinal strain was measured by the extensometer, the Poisson ratio was assumed to be equal to 0.31 and to not depend on the test 
temperature. Such an assumption was rather relevant according to the literature, given that the Poisson ratio for Inconel@600 varies in the range of 0.30-0.32 between room temperature and $800^{\circ} \mathrm{C}$ (http://www.specialmetals.com/products/inconelalloy600.php). Similarly, since the mean values measured for the Young modulus were in a very good agreement with those of the literature (see Table 2), we set the Young modulus to be equal to that of the literature for the fitting procedure (in order to improve the identification of the yield stress and the beginning of the plasticity). Coefficients $b_{1 m}, b_{2 m}$ and $b_{3 m}$ were also fixed, since some first estimations of their values showed that these parameters were quite independent from the test conditions (temperature and obviously the strain rate). They were set to 500, 50 and 5, respectively, to account for various non-linearity regimes associated with different strain ranges.

Table 3: Mechanical properties of Inconel@ 600 identified from the tensile tests on single tubes.

\begin{tabular}{llll}
\hline & $\mathrm{RT}$ & $600^{\circ} \mathrm{C}$ & $800^{\circ} \mathrm{C}$ \\
\hline$E_{m}$ (fixed) & $214.0 \mathrm{GPa}$ & $180.0 \mathrm{GPa}$ & $164 \mathrm{GPa}$ \\
$\nu_{m}$ (fixed) & 0.31 & 0.31 & 0.31 \\
$\sigma_{y m}$ & $223.1 \mathrm{MPa}$ & $145.7 \mathrm{MPa}$ & $114.6 \mathrm{MPa}$ \\
$Q_{1 m}$ & $7.6 \mathrm{MPa}$ & $11.9 \mathrm{MPa}$ & $12.4 \mathrm{MPa}$ \\
$b_{1 m}$ (fixed) & 500.0 & 500.0 & 500.0 \\
$Q_{2 m}$ & $37.8 \mathrm{MPa}$ & $12.5 \mathrm{MPa}$ & $133.2 \mathrm{MPa}$ \\
$b_{2 m}$ (fixed) & 50.0 & 50.0 & 50.0 \\
$Q_{3 m}$ & $482.5 \mathrm{MPa}$ & $495.6 \mathrm{MPa}$ & $13.3 \mathrm{MPa}$ \\
$b_{3 m}$ (fixed) & 5.0 & 5.0 & 5.0 \\
$n_{m}$ & 56.6 & 56.6 & 3.9 \\
$D_{m}$ & $606.2 \mathrm{MPa} . \mathrm{s}^{\frac{1}{n_{m}}}$ & $606.2 \mathrm{MPa} . \mathrm{s}^{\frac{1}{n_{m}}}$ & $1228.3 \mathrm{MPa} . \mathrm{s}^{\frac{1}{n_{m}}}$ \\
\hline
\end{tabular}

The aforementioned fitting procedure was then applied at $800^{\circ} \mathrm{C}$. Similarly to the fits at room temperature and $600^{\circ} \mathrm{C}$, the Young modulus was set to its literature value, whereas the Poisson ratio and the $b_{i m}$ were set to the same values as before (i.e. 0.31, 500, 50, and 5 , respectively). Obviously, at $800^{\circ} \mathrm{C}$ the stress-strain curves were fitted simultaneously, but this time distinguishing each strain rate to account for viscosity. The constitutive properties determined for the three different test temperatures are provided in Table 3. The fitted stressstrain curves are plotted with the experimental ones in Figs. 4(a) and 4(b).

It is worth noting that the constitutive bi-potential elasto-viscoplatic model proposed ob- 
tains the various features of the mechanical behavior observed for Inconel@ 600 very well. At room temperature and $600^{\circ} \mathrm{C}$, the values identified for $n_{m}$ are high, thus the viscosity contribution can be considered as negligible. On the contrary, at $800^{\circ} \mathrm{C}$ this value is equal to 3.9 , which is classical for Ni-base superalloys. As concerns the hardening capabilities, the yield stress decreases significantly when the test temperature is increased. Moreover, the total hardening

capability value (i.e. $\sum_{i=1}^{3} Q_{i m}$ ) decreases when the test temperature is also increased and is more than twice as high at room temperature and $600^{\circ} \mathrm{C}$ as at $800^{\circ} \mathrm{C}$. At room temperature and $600^{\circ} \mathrm{C}$, the main contribution to the total hardening is that related to high strain levels $\left(Q_{3 m}\right)$, whereas at $800^{\circ} \mathrm{C}$ it is that related to medium strain levels $\left(Q_{2 m}\right)$. Therefore, the hardening saturation is more important at $800^{\circ} \mathrm{C}$, but it is offset by an additional viscous strain. It can also be noticed that the experimental values measured for $\sigma_{0.2 m}$ cannot correspond to $\sigma_{y m}$ by definition and because of the fast hardening contribution $Q_{1 m}$. They are rather comprised between $\sigma_{y m}+Q_{1 m}$ and $\sigma_{y m}+Q_{1 m}+Q_{2 m}$.

\section{Post-mortem microstructural characterization}

In order to investigate microstructural changes resulting from the tensile tests, post-mortem EBSD analyses have been carried out on tested samples.

\subsection{Sample preparation}

One of the two parts of the broken tubes was cut in a longitudinal median plane. The cut tubes were cold-mounted in an epoxy resin and polished flat in a plane parallel to the tube axis (Fig. 5). The analyzed surface was chosen to set the tube axis parallel to the transversal direction (TD) of the conventional crystallographic macroscopic frame. As a result, TD was parallel to the load direction and the normal direction (ND) of the conventional crystallographic macroscopic frame corresponded to a direction transverse to that of the load. The scanning was performed near the fracture area and the EBSD patterns were indexed in the face-centered 
cubic lattice corresponding to the crystallographic system of nickel (space group: Fm3m). A grain was defined as a group of at least five neighboring indexed points having the same crystal orientation within a tolerated angular deviation of $5^{\circ}$. In order to highlight the crystallographic evolution resulting from the test conditions, two microstructures were compared: Sample 1 (NHT, $0.4 \mathrm{~mm} \mathrm{~min}^{-1}$ at RT) and Sample 21 (BHT, $47.0 \mathrm{~mm} \mathrm{~min}^{-1}$ at $800^{\circ} \mathrm{C}$ ). For the all scans, outer surface of the tubes is at the top, whereas inner surface is at the bottom. Moreover, height of scans is not the same because the area reduction at the final stage of the rupture was considerably higher for sample 21 (tested at $800^{\circ} \mathrm{C}$ ) than fo sample 1 (tested at RT), hence thinner tube walls.

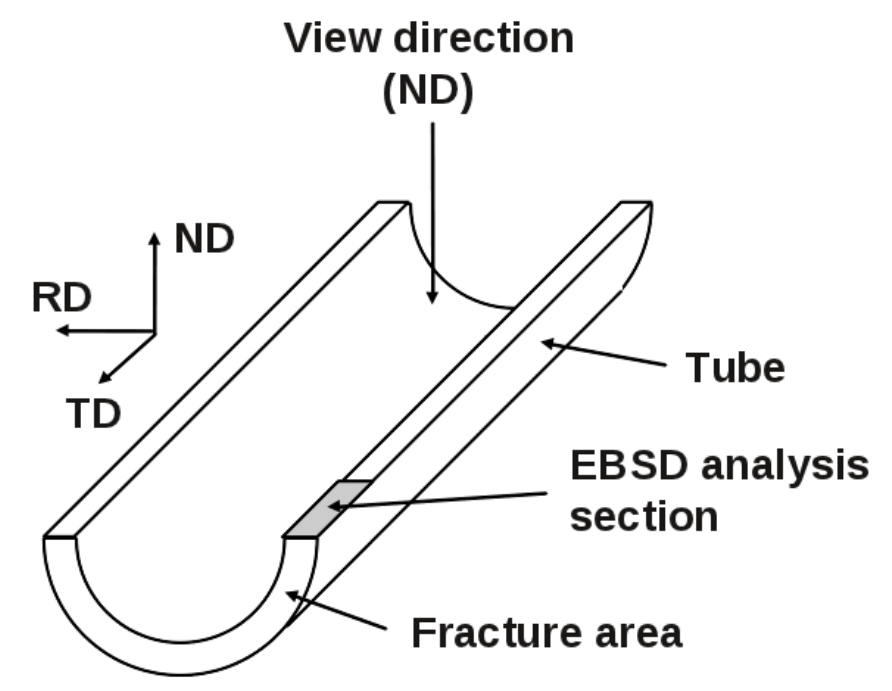

Figure 5: Schematic illustration of the EBSD analyzed section.

\subsection{EBSD analyses}

EBSD analyses revealed a grain morphology typical of highly-strained materials (see Fig. 6). The inverse pole figures referring to TD and ND (IPF TD and IPF ND, respectively) are given in Fig. 6 too. The grains are elongated toward the load direction, i.e., the tubular specimen axis. The deformation spreads over the entire surface analyzed and textures are observed both in TD and ND resulting from the rotation of the slip systems in the grains during the plastic deformation of the tubes. IPF TD shows that there were two preferential orientations of the 
cubic unit cell: a major $<111>$ direction in blue, and a minor $<100>$ direction in red, as given by the corresponding key color. It means that either the diagonal or the edge of the facecentered cubic lattice was parallel to TD. These two preferential orientations were also revealed by the direct pole figures. Indeed, (001) and (111) plane pole figures show intensity peaks in the directions close to TD. The orientation mapping referring to ND also revealed a texture. It appeared that the grains are mostly green, meaning that $<101>$ direction was preferentially parallel to ND. This particular texture resulted from the tubular shape of the specimens and the ductility of their constitutive material: both longitudinal and transverse deformations occurred at the final stage of the rupture, leading to a large reduction in the tube diameter locally.

EBSD analyses also revealed a heterogeneous grain size in the thickness of the tube walls. The finer grain microstructure observed at the inner and outer surfaces of the tubes can be explained by a higher plastic deformation locally, resulting from the initial cold drawing process of the tubes. The tubes are drawn through a mould, using a guide bar to keep the tube straight and to give the inner diameter after drawing. Thus, during this process the outer diameter and the wall-thickness of the tube are reduced resulting in a significant plastic deformation in the material at the end of processing. Grain size is quickly reduced by the successive cold drawing and annealing sequences.

\subsection{Residual strain analysis}

In addition of the crystallographic information previously described (texture and grain size), EBSD data post-treatment can also provide information on the residual plastic strains into the grains. The technique enables analyses with high spatial resolution and sensitive examination of the plastic strain, which are otherwise difficult to obtain by X-ray diffraction or transmission electron microscopy because of either spatial / angular resolution or sampling limitations, respectively. For instance, interesting qualitative maps describing the organization of the defect density can be established through the kernel average misorientation (KAM) analysis. KAM has been used to represent the average misorientation between a given point of measure and 

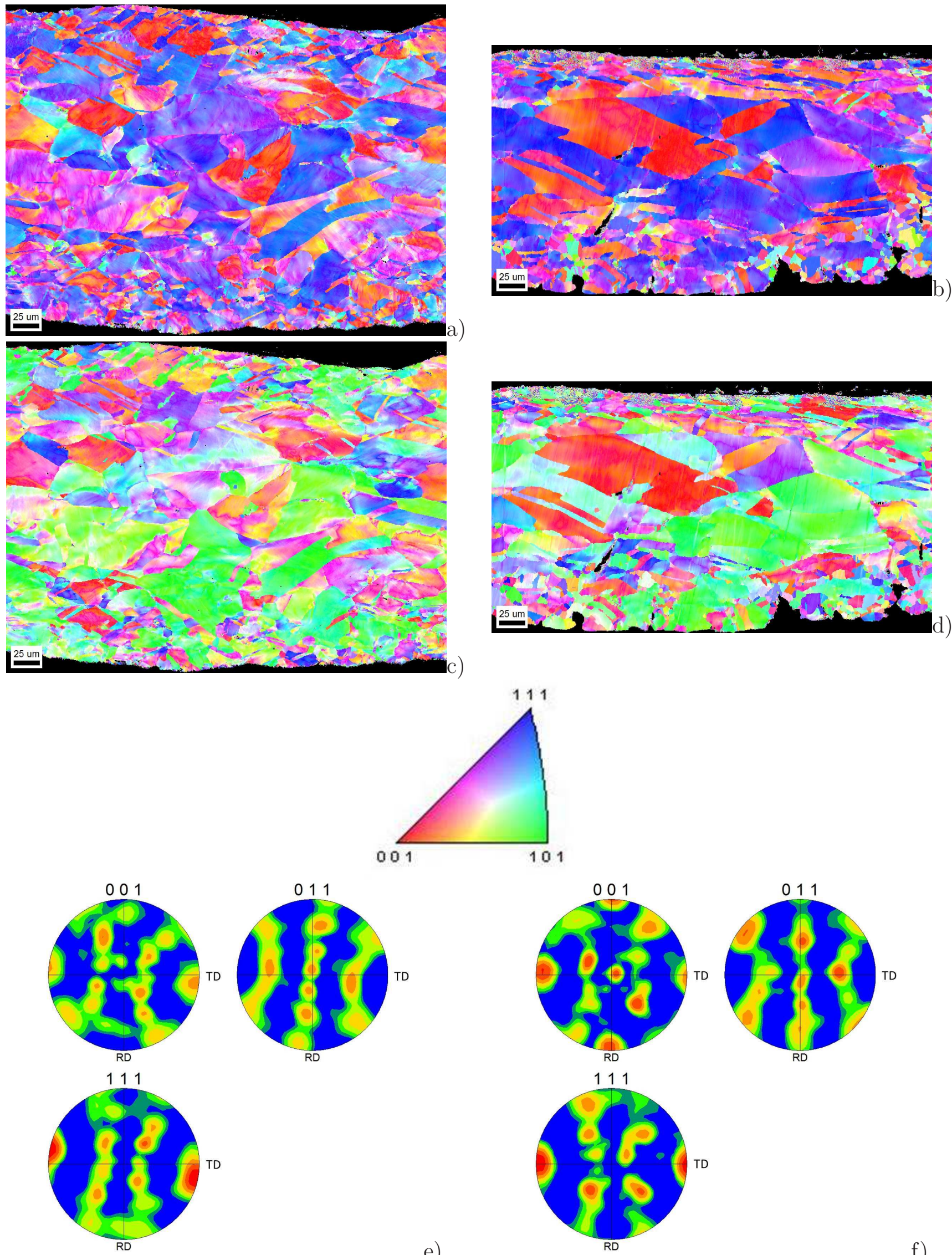

Figure 6: EBSD analysis of samples 1 and 21: IPF referring to TD (top figures) and ND (middle figures) of the crystallographic macroscopic frame, the corresponding key color and direct pole figures (bottom figures). Sample 1 is on the left whereas sample 21 is on the right. 
its nearest neighbors that belongs to the same grain. Another quantity, the grain orientation spread (GOS, i.e., the average orientation deviation between each point in a grain and the average orientation of the grain), has also been determined in each grain. Thus, GOS maps clearly show the most strained grains, whereas KAM maps rather provide the local density of dislocations. The blue color in all of the maps indicates very slight misorientations. The green, yellow, orange and red colors represent progressively increasing levels of internal or local misorientations. Grains are outlined with black boundaries. The same color scales, misorientations from 0 to $18^{\circ}$ for the GOS and from 0 to $5^{\circ}$ for the KAM, are used for the two samples in Fig. 7. Note that for the GOS analysis, twin boundaries have been considered as grain boundaries.

Fig. 7 clearly shows that the residual strains into the grains were lower for Sample 21, which was deformed at $800^{\circ} \mathrm{C}$, than for Sample 1, which was deformed at room temperature. In particular, both GOS and KAM maps obtained for Sample 1 indicate that a large amount of strain energy has been stored in the material during the test by forming dislocations. The analysis of the GOS map obtained for Sample 21 also shows a majority of grains colored in green and a family of small grains colored in blue at the bottom of the image, i.e., the inner surface of the tube. They result from dynamic recrystallization that occurred during the tests at $800^{\circ} \mathrm{C}$. Recrystallization occurrence has been confirmed by the fact that no texture was observed in these grains on both the IPF TD and ND given in Fig. 6. In the GOS maps of both samples, small grains colored in blue and dispersed into the tube wall were also observed, revealing the presence of precipitate phases. The largest precipitates were titanium nitrides, which present a crystalline structure similar to that of Inconel@600, titanium atoms in titanium nitrides forming a cubic lattice with centered faces. Due to the fact that they are brittle, they broke during the tests, and small levels of residual strains were observed. The comparison between the KAM maps obtained for the two samples reveals a lower density of dislocations in the grains in the middle area for the tube tested at $800^{\circ} \mathrm{C}$ (Sample 21 ). This can be explained by dynamic recovery phenomena occurring during the tensile tests at $800^{\circ} \mathrm{C}$ even at $47.0 \mathrm{~mm} \mathrm{~min}^{-1}$. Competition between work-hardening on one side and both 

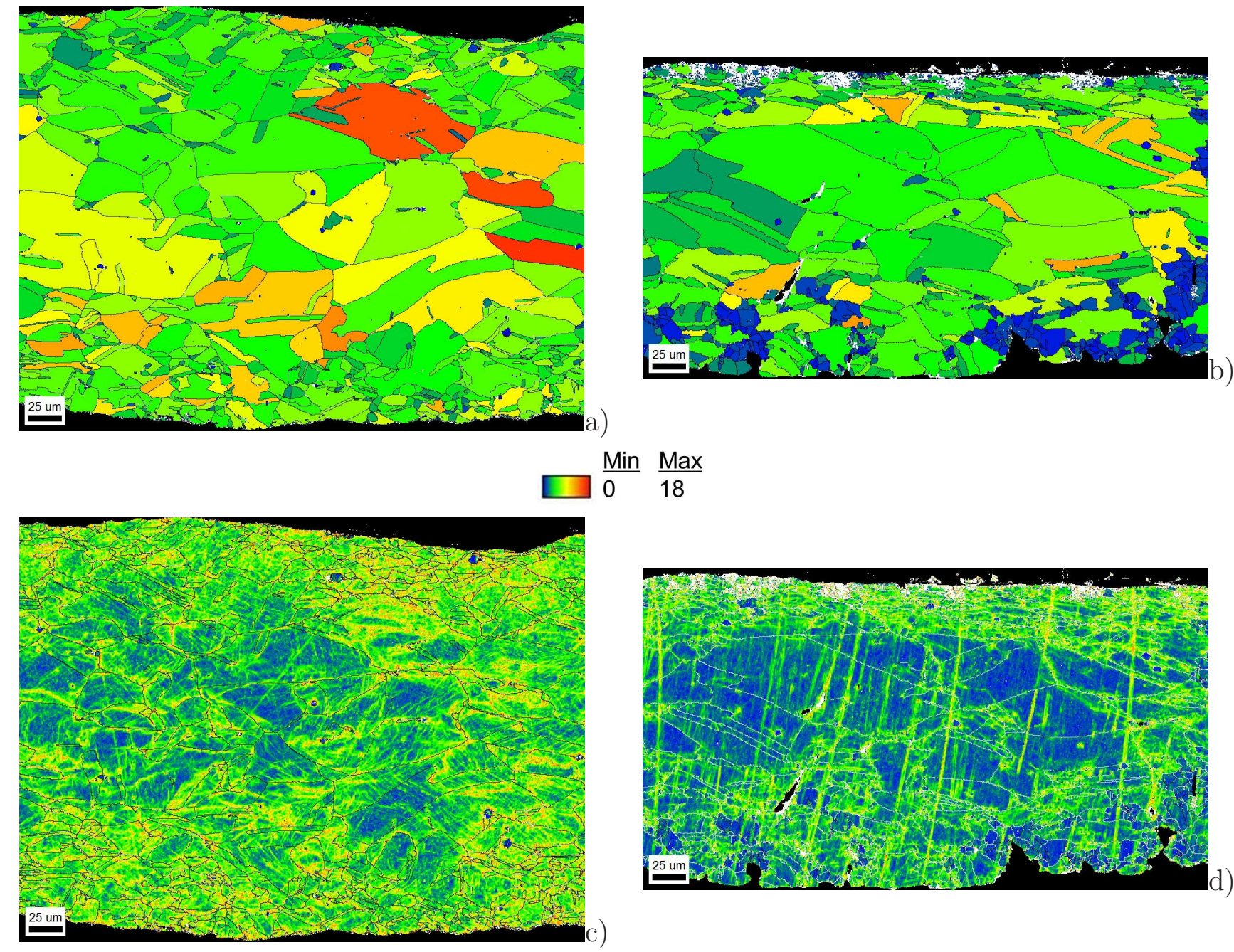

$\frac{\operatorname{Min}}{0} \frac{\operatorname{Max}}{18}$

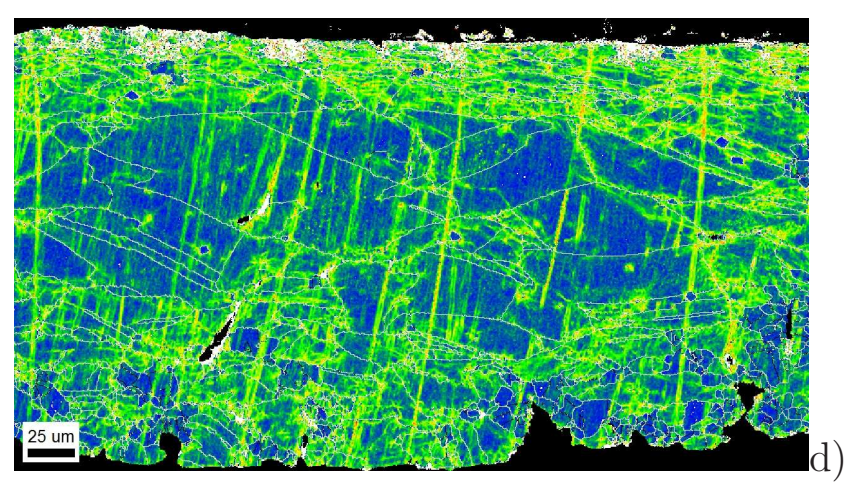

$\frac{\operatorname{Min}}{0} \frac{\operatorname{Max}}{5}$

Figure 7: GOS and KAM maps for the two analyzed samples (1 and 21) and their corresponding color scale. GOS maps are top figures whereas KAM maps are bottom ones. Sample 1 is on the left whereas sample 21 is on the right. (d) Large vertical straight lines observed in the KAM map obtained for sample 21 only are artefacts resulting from the polishing process. 
dynamic recrystallization and recovery on the other side took place during the tests, these last two mechanisms being more or less present depending on the strain rate. These results are consistent with the viscosity effect presented in Section 3.1 (see Figs. 3(a) and 3(b)). For the lower strain rates $\left(0.4 \mathrm{~mm} \mathrm{~min}^{-1}\right.$ and $\left.4.5 \mathrm{~mm} \mathrm{~min}^{-1}\right)$, the kinetics of dynamic recovery at $800^{\circ} \mathrm{C}$ suffice to allow the annihilation of the dislocations and, as a result, only a slight

strain hardening is observed. On the contrary, for the highest strain rate $\left(47.0 \mathrm{~mm} \mathrm{~min}^{-1}\right)$, the test elapses too fast to allow complete dynamic recrystallization and recovery, hence work hardening and plasticity predominate. At lower temperatures, it can be expected that dynamic recrystallization and recovery cannot be thermally activated, thus the absence of any observed viscous effect whatever the strain rate.

\section{Conclusions}

This work has concerned both the mechanical and microstructural characterizations of Inconel@600, as constitutive material of a cellular structure consisting of stacked and brazed tubes, from room temperature to $800^{\circ} \mathrm{C}$.

For that purpose, tensile tests at various strain rates and temperatures have been performed. They have shown the strong influence of the brazing heat treatment on the elasto-viscoplastic behavior of Inconel@600. The tubes having been strongly hardened during their cold drawing process, the brazing heat treatment acts as a recovery one, hence a lower yield stress and higher hardening capabilities. The test temperature has a significant influence too. By increasing, it results in a decrease of the strength of Inconel(R600. Moreover, at the highest test temperature, the difference between the mechanical response of the as-received tubes and that of the heattreated ones tends to vanish. Viscosity has been revealed only at the highest test temperature. Post-mortem EBSD observations carried out have shown that both dynamic recrystallization and recovery occur during the tensile tests performed at $800^{\circ} \mathrm{C}$. The competition between workhardening on one side and dynamic recrystallization and recovery on the other side at $800^{\circ} \mathrm{C}$ results in a strong viscosity. For the lower strain rates, the thermal energy supplied during the 
tests allowed the system to use the strain energy stored during the processing of the tube to limit the strain hardening. This was no more true in the case of the higher strain rate at $800^{\circ} \mathrm{C}$, for which dynamic recrystallization and recovery had no longer enough time to be complete. In that case, work-hardening and plasticity were predominant. Obviously, for the two lower temperatures considered in this study, work-hardening and plasticity were also predominant whatever the strain rate. From these tensile tests, elasto-viscoplastic properties have then been identified for each test temperature (room temperature, $600^{\circ} \mathrm{C}$ and $800^{\circ} \mathrm{C}$ ) assuming a bi-potential to distinguish the respective contributions of the plasticity and the viscosity, and to capture the viscous effect saturation observed when increasing the strain rate. A non-linear hardening has been used to account for a hardening saturation in the modeling.

In the following, the mechanical properties of Inconel@600 characterized here have been used as input data for the modeling of the compression behavior of the aforementioned tube stacking structure. These results are detailed in a companion paper addressing both experimental and numerical characterizations of the high temperature behavior of tube stackings (see Part II [7]).

\section{Acknowledgements}

This work was performed within the 'Aero-Thermodynamic Loads on Lightweight Advanced Structures II' project investigating high-speed transport. ATLLAS II, coordinated by ESAESTEC, was supported by the European Union within the 7th Framework Program Theme 7 Transport, Contract No.: ACP0-GA-2010-263913. Further information on ATLLAS II can be found at http://www..esa.int/techresources/atllas_II. We are also indebted to our colleagues M. Thomas, P. Kanouté and S. Kruch for many fruitful discussions. 


\section{References}

[1] A.G. Evans, J.W. Hutchinson, M.F. Ashby, Multifunctionality of cellular metal systems, Cambridge University Press, 1997.

[2] A. Ochsner, C. Augustin et al., Multifunctional metallic hollow sphere structures: manufacturing, properties and application, Springer, 2009.

[3] V. Marcadon, B. Passilly, C. Davoine, A. Götzfried, F.H. Leroy, About the use of microindentation to determine the constitutive material's mechanical behavior of cellular structures, EPJ Web Conf. 6 (2010), 04003.

[4] V. Marcadon, C. Davoine, B. Passilly, D. Boivin, F. Popoff, A. Rafray, S. Kruch, Mechanical behavior of hollow-tube stackings: Experimental characterization and modeling of the role of their constitutive material behavior, Acta Mater. 60 (2012) 5626-5644.

[5] S.D. Papka, S. Kyriakides, Biaxial crushing of honeycombs - Part I: Experiments, Int. J. Solids Struct. 36 (1999) 4367-4396.

[6] S.D. Papka, S. Kyriakides, In-plane biaxial crushing of honeycombs - Part II: Analysis, Int. J. Solids Struct. 36 (1999) 4397-4423.

[7] V Marcadon, D. Lévêque, A. Rafray, F. Popoff, D. Mézières, C. Davoine, High temperature mechanical behavior of tube stackings - Part II: Comparison between experiment and modeling, Mater. Sci. Eng. A, to be published

[8] G. P. Airey, Microstructural Aspects of the Thermal Treatment of Inconel Alloy 600, Metallography 13 (1980) 21-41.

[9] H.-B. Park, Y.-H. Kim, B.-W. Lee, K. S. Rheem, Effect of heat treatment on fatigue crack growth rate of Inconel 690 and Inconel 600, J. Nucl. Mater. 231 (1996) 204-212.

[10] S.M. Bruemmer, C.H. Henager, High voltage electron microscopy observations of microdefformation in alloys 600 tubing, Scripta Metall. 20 (1986) 909-914. 
[11] J.D. Wang, D. Gan, Effects of grain boundary carbides on the mechanical properties of Inconel 600, Mater. Chem. Phys. 70 (2001) 124-128.

[12] E.L. Hall, C.L. Briant, The Microstructural Response of Mill-Annealed and SolutionAnnealed INCONEL 600 to Heat Treatment, Metall. Trans. A 16 (1985) 1225-1236.

[13] M. Ivanchenko, V. Nevdacha, Y. Yagodzinskyy, H. Hanninen, Internal friction studies of carbon and its redistribution kinetics in Inconel 600 and 690 alloys under dynamic strain aging conditions, Mater. Sci. Eng. AMaterials Science and Engineering A 442 (2006) 458461.

[14] B. Li, S. Tin, The role of deformation temperature and strain on grain boundary engineering of Inconel600, Mater. Sci. Eng. A 603 (2014) 104-113.

[15] K.H. Song, H. Fujii, K. Nakata, Effect of welding speed on microstructural and mechanical properties of friction stir welded Inconel 600, Mater. Design 30 (2009) 3972-3978.

[16] J. Blaizot, T. Chaise, D. Nelias, M. Perez, S. Cazottes, P. Chaudet, Constitutive model for nickel alloy 690 (Inconel 690) at various strain rates and temperatures, Int. J. Plasticity 80 (2016) 139-153.

[17] E. Amsterdam, J.H.B. deVries, J.Th.M. deHosson, P.R. Onck, The influence of straininduced damage on the mechanical response of open-cell aluminum foam, Acta Mater. 56 (2008) 609-618.

[18] E. Amsterdam, J.Th.M. deHosson, P.R. Onck, On the plastic collapse stress of open-cell aluminum foam, Scripta Mater. 59 (2008) 653-656.

[19] K.R. Mangipudi, S.W. vanBuuren, P.R. Onck, The microstructural origin of strain hardening in two-dimensional open-cell metal foams, Int. J. Solids Struct. 47 (2010) 2081-2096.

[20] J. Besson, G. Cailletaud, J.L. Chaboche, S. Forest, Non-Linear Mechanics of Materials (Solid Mechanics and Its Applications), Springer, 2010. 
[21] I.J. Perrin, D.R. Hayhurst, Creep constitutive equations for a 0.5Cr-0.5Mo-0.25V ferritic steel in the temperature range 600-675 C, J. Strain Anal. Eng. Design 31 (1996) 299-314.

[22] F. Vakili-Tahami, D.R. Hayhurst, M.T. Wong, High-temperature creep rupture of low alloy ferritic steel butt-welded pipes subjected to combined internal pressure and end loadings, Plilos. Trans. R. Soc. London 363 (2005) 2629-2661.

[23] J.-L. Chaboche, A. Gaubert, P. Kanouté, A. Longuet, F. Azzouz, M. Mazière, Viscoplastic constitutive equations of combustion chambers materials including cyclic hardening and strain aging, Int. J. Plasticity 46 (2013) 1-22.

[24] R.A. Barrett, P.E. O’Donoghue, S.B. Leen, An improved unified viscoplastic constitutive model for strain-rate sensitivity in high temperature fatigue, Int. J. Fatigue 48 (2013) 192-204.

[25] R.A. Barrett, T.P. Farragher, C.J. Hyde, N.P. O’Dowd, P.E. O’Donoghue, S.B. Leen, A unified viscoplastic model for high temperature low cycle fatigue of service-aged P91 steel, J. Press. Vessel Technol. 136 (2014) 021402.doi:10.1115/1.4024618. 